\title{
PERFIL EPIDEMIOLÓGICO DA DENGUE NO MUNICÍPIO DE ILHA SOLTEIRA, SÃO PAULO, NO PERÍODO DE 2016 A 2018
}

\author{
SILVA, Iara Tamaki ${ }^{1}$ \\ TAGLIAFERRO, Evandro Roberto ${ }^{2}$ \\ VAZQUEZ, Gisele Herbst ${ }^{3}$ \\ FRIAS, Danila Fernanda Rodrigues ${ }^{4}$
}

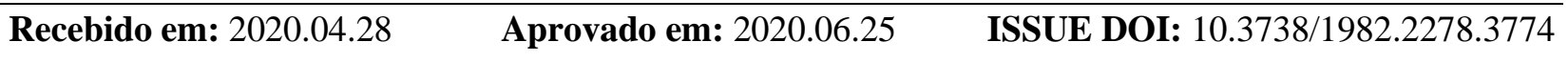

RESUMO: A dengue caracteriza-se como uma doença infecciosa viral aguda transmitida pela picada do mosquito Aedes aegypti, sendo um importante problema de saúde pública. O presente trabalho teve por objetivo descrever o perfil epidemiológico da dengue no município de Ilha Solteira, no período entre 2016 a 2018. Foi realizado estudo descritivo retrospectivo com levantamento de dados registrados em fichas de notificação do Sistema de Informação de Agravos de Notificação (SINAN). As variáveis utilizadas para o estudo foram: número de casos notificados e confirmados entre os meses dos anos pesquisados, distribuição dos casos quanto ao sexo, idade, raça, zona de residência e evolução dos casos. No período investigado foram notificados 1019 casos suspeitos de dengue, sendo $79,4 \%$ dos casos confirmados. O maior número de casos aconteceu nos cinco primeiros meses do ano, atingindo em sua maioria indivíduos entre 40 - 44 anos, sendo as mulheres as mais afetadas. Os bairros da Zona Norte foram os que mais apresentaram notificações. O município de Ilha Solteira possui altas taxas de incidência da doença, com variação anual para maior ou menor número de casos, sendo considerado endêmico para a dengue. Essa constatação leva a necessidade de organizar os serviços de saúde de Atenção Básica por meio de melhorias das ações de enfrentamento à doença, realizando um chamamento da população para realizar ações diárias em seu domicilio e peridomicílio a fim de diminuir os números de casos.

Palavras-chave: Aedes aegypti, Atenção Básica, Endêmico.

\section{EPIDEMIOLOGICAL PROFILE OF DENGUE IN THE MUNICIPALITY OF ILHA SOLTEIRA, SÃO PAULO, FROM 2016 TO 2018}

SUMMARY: Dengue is characterized as an acute viral infectious disease transmitted by the bite of the Aedes aegypti mosquito, being an important public health problem. The present study aimed to describe the epidemiological profile of dengue in the municipality of Ilha Solteira, from 2016 to 2018 . A retrospective descriptive study was carried out with data recorded the Severe Notification Information System (SINAN). The variables used for the study were: number of reported and confirmed cases among the months of the surveyed years, distribution of cases regarding gender, age, race, area of residence, and case evolution. In the investigated period 1019 suspected cases of dengue were reported, $79.4 \%$ of the cases being confirmed. The highest number of cases occurred in the first five months of the year, mainly affecting individuals between 40 and 44 years and women. The North Zone neighborhoods were the ones that presented the most notifications. The municipality of Ilha Solteira has high incidence rates of the disease, with annual variation for more or less cases, being considered endemic for dengue. This observation leads to the need to organize the Basic Care health services through improvements in the actions to confront the disease, calling on the population to carry out daily actions in their homes and peridomicide in order to reduce the number of cases.

Keywords: Aedes aegypti, Basic Care, Endemic.

\footnotetext{
${ }^{1}$ ORCID - http://orcid.org/0000-0002-8511-4087

${ }^{2}$ ORCID - http://orcid.org/0000-0003-2557-031X

${ }^{3}$ ORCID - http://orcid.org/0000-0002-0957-329X

${ }^{4}$ ORCID - http://orcid.org/0000-0001-8621-3338
} 


\section{INTRODUÇÃO}

A dengue é a arbovirose mais importante no Brasil, e a mais prevalente no mundo, pois $40 \%$ da população está sob o risco de contágio. Quatro sorotipos do vírus estão em circulação atualmente, são eles, DENV 1, DENV 2, DENV 3, e DENV 4, o que aumenta significativamente as formas graves e letais da doença (VIANA; IGNOTTI, 2013).

Dentre as doenças reemergentes, a dengue é a que constitui o problema mais grave de saúde pública, pois cerca de 2,5 bilhões de pessoas no mundo estão expostas ao risco de se infectarem, principalmente em países de clima tropical, onde a temperatura e a umidade favorecem a proliferação do vetor (TAUIL, 2002; OMS, 2009).

Segundo o Ministério da Saúde, nos últimos 50 anos, a incidência da doença aumentou 30 vezes devido à expansão geográfica e nesta década, atingiu pequenas cidades e áreas rurais. Estima-se que 50 milhões de casos de infecção por dengue ocorram anualmente e que aproximadamente 2,5 bilhões de pessoas vivem em países onde a dengue é endêmica (BRASIL, 2015).

A proliferação da doença é facilitada por condições socioambientais, destacando-se as alterações climáticas como o aquecimento global, impactos ambientais nas paisagens e nos ecossistemas, à urbanização da população, a industrialização crescente, os novos modelos e estilos de vida da população com o aumento do consumo e consequente geração elevada de resíduos, o enfraquecimento dos serviços de saúde pública. Além de todos esses fatores há também a variação genética do patógeno (COSTA et al., 2012).

No Brasil, o surto da doença está relacionado a variáveis meteorológicas, aparecendo nos primeiros cinco meses do ano, período mais quente e úmido, próprio de países de clima predominantemente tropical (VIANA; IGNOTTI, 2013).

$\mathrm{Na}$ região Noroeste do estado de São Paulo o vetor encontrou ambiente bastante favorável, tanto pela oferta de criadouros, como pelas condições climáticas adequadas: altas temperaturas e principalmente grande incidência de chuvas entre os meses de novembro e abril (TANNOUS, 2018). A confirmação do sorotipo DENV 4 ocorreu no primeiro semestre de 2011 em alguns municípios do Noroeste Paulista (SECRETARIA DE ESTADO DA SAÚDE, 2011).

A dengue é um agravo importante à saúde da população, que vive em sua maioria, nas áreas urbanas dos municípios brasileiros, constituindo assim um desafio para os gestores municipais, pois o combate ao vetor envolve ações continuadas de inspeções domiciliares, eliminação e tratamento de criadouros, associados a atividades de educação em saúde e mobilização social a fim de manter a infestação do vetor com níveis incompatíveis com a transmissão da doença (BRASIL, 2010). 
Para controle e prevenção efetivos da doença, deve-se organizar previamente o sistema de saúde de modo a monitorar sua distribuição e disseminação em períodos pré-determinados, detectando-se a iminência de uma epidemia e avaliando seu impacto sobre a comunidade (BRASIL, 2009).

Para estabelecer o perfil epidemiológico da dengue no município de Ilha Solteira, torna-se necessário conhecer os aspectos do agravo, sua história, epidemiologia, etiologia, aspectos clínicos e outros elementos que permitam o seu reconhecimento enquanto fator de grande preocupação para a população em geral.

Desta forma, o presente trabalho teve por objetivo analisar o perfil epidemiológico dos casos de dengue notificados em Ilha Solteira, São Paulo, no período de 2016 a 2018, visando indicar estratégias de ação com o objetivo de controlar e prevenir a ocorrência da doença no Município.

\section{MATERIAL E MÉTODO}

Foi realizado estudo epidemiológico de abordagem descritiva retrospectiva, com natureza quantitativa de séries temporais da ocorrência e distribuição dos casos de dengue em Ilha Solteira, São Paulo. O levantamento de dados foi efetuado em 1019 fichas de notificação do SINAN (Sistema de Informação de Agravos de Notificação) e boletins informativos da Vigilância Sanitária do Município, relacionados aos casos de dengue nos anos de 2016, 2017 e 2018. As fichas de investigação de dengue foram disponibilizadas pela Secretaria de Saúde do Município de Ilha Solteira por meio do Setor de Vigilância Sanitária (SVS), após autorização do Secretário de Saúde.

A pesquisa foi efetuada na cidade de Ilha Solteira, município com aproximadamente 26.582 habitantes, que faz parte do DRS - Departamento Regional de Saúde de Araçatuba, que atende 40 municípios, perfazendo um total de 719.323 habitantes (SECRETARIA DE ESTADO DA SAÚDE, 2019).

Ilha Solteira é um município brasileiro localizado no interior do estado de São Paulo. Pertence à Mesorregião de Araçatuba, próximo ao encontro dos rios Tietê e Paraná e à divisa com o Estado do Mato Grosso do Sul. A cidade fica próxima a hidrovia Tietê-Paraná, uma das mais importantes hidrovias de transporte do MERCOSUL (PREMISA, 2012).

O clima do município é classificado como tropical chuvoso de bosque, marcado por chuvas de verão e estiagem no inverno. A temperatura média anual é de $23,6^{\circ} \mathrm{C}$, e o índice pluviométrico é de $1.300 \mathrm{~mm}$ anuais (PREMISA, 2012). 
Para a realização deste trabalho foi feito um levantamento dos dados da doença no município junto à Vigilância Sanitária municipal onde foram obtidos dados referentes aos últimos 3 anos, constatando: número absoluto de casos por ano, por mês, distribuição por idade, gênero, bairro, sintomas apresentados, classificação final e evolução da doença.

Após realização do diagnóstico de situação, os dados obtidos foram digitalizados e tabulados em planilhas do software Microsoft Office Excel ${ }^{\circledR}$ versão 2016 e formaram o banco de dados utilizado para análise. Os dados foram analisados por meio de cálculo de médias simples, número absoluto e porcentagem calculadas também pelo Microsoft Office Excel ${ }^{\circledR}$ versão 2016, e os resultados foram apresentados em formato de gráficos.

\section{RESULTADO E DISCUSSÃO}

\section{Número de casos notificados durante o período de estudo}

A partir dos dados coletados do SINAN e boletins informativos foi possível observar que no período de 2016 a 2018, foram notificados no município de Ilha Solteira 1019 casos suspeitos de dengue. A distribuição anual das notificações foi de 596 em 2016, 48 em 2017 e 375 em 2018.

O ano em que ocorreu maior número de notificações foi em 2016, perfazendo 58,5\% do total. Nos anos subsequentes notou-se uma queda acentuada no número de notificações, concentrando-se 4,7\% em 2017 e novamente aumento em 2018, com 36,8\% das notificações do período. Devido a esta alteração de perfil, o município foi caracterizado como interepidêmico.

A queda brusca do número de notificações em 2017 pode estar relacionada as ações de controle do vetor efetuadas em 2016 durante o surto de dengue que ocorreu no município, como também a recirculação do sorotipo viral que já afetava a cidade ou até mesmo subnotificação da doença. Em contrapartida, a elevação dos casos em 2018 pode indicar a não intensificação de campanhas e mobilização de prevenção e controle, melhor efetividade de notificações ou até mesmo a reintrodução ou introdução de um sorotipo viral.

Um dado cuja falta foi observada neste estudo é a realização da tipificação do sorotipo viral em circulação no município. Esta informação é muito importante pois qualquer sorotipo pode causar a doença de forma branda, grave e até mortal. Além disso, a infecção uma vez adquirida confere imunidade permanente aquele sorotipo viral e imunidade parcial aos outros. Porém, a infecção subsequente aumenta o risco de ocorrência da forma grave da doença, neste caso a febre hemorrágica do dengue (WHO, 2016).

Como a dengue é uma doença viral e que acomete número elevado de indivíduos durante sua fase endêmica, é essencial que todos os casos sejam notificados para que os órgãos de 
vigilância sanitária estabeleçam o perfil epidemiológico da doença. É um agravo de notificação compulsória (Portaria GM/MS nº 2.72 de 31 de agosto de 2010). Desta forma, todos os casos suspeitos, confirmados ou não, devem ser notificados à Vigilância Epidemiológica do município (BRASIL, 2010).

Em Ilha Solteira, a população estimada em 2016 era de 26.540 habitantes, o que demonstrou incidência de notificações de 2,245 casos a cada 100 mil habitantes, número este elevado quando comparado a dados encontrados no Brasil, onde o ano de 2016 apresentou índices altos de notificações, totalizando 1.496.282 casos prováveis de dengue, com incidência 731 casos a cada 100 mil habitantes, e em Alagoas, que a incidência de dengue apresentou uma no município de Ilha Solteira taxa de 427,4 casos por 100.000 habitantes também em 2016 (SESAU, 2017; IBGE, 2019; LEAL, 2017).

Em 2017, a incidência de notificações no município estudado baixou para 180 casos a cada 100 mil habitantes. Já no Brasil, foram registrados 249.056 casos prováveis de dengue, com uma incidência de 120,9 casos/100 mil habitantes (BRASIL, 2018).

Em 2018, a incidência de notificações voltou a subir, apresentando-se 1.412 casos/100 mil habitantes. No Brasil, no mesmo período foram registrados 247.393 casos prováveis de dengue, com uma incidência de 118,7 casos/100 mil habitantes (BRASIL, 2018).

A dengue é uma doença muito importante e de elevada ocorrência. Em Minas Gerais, um estudo demonstrou que entre 2011 e 2012, a doença apareceu em quinto lugar, com 38.792 notificações (SILVA et al., 2014). Ilha Solteira demonstrou elevado número de notificações quando avaliada a incidência na população, assim como o que foi constatado em 2016, no município de Ribeirão Preto/SP, pois a dengue alcançou seu auge, com a taxa de notificação de 5.196 casos por 100 mil habitantes, além de 8 óbitos (GABRIEL et al., 2018).

Figura 1. Casos notificados de dengue segundo a média mensal dos anos da série histórica de 2016 a 2018 em Ilha Solteira. Ilha Solteira, São Paulo, Brasil, 2020.

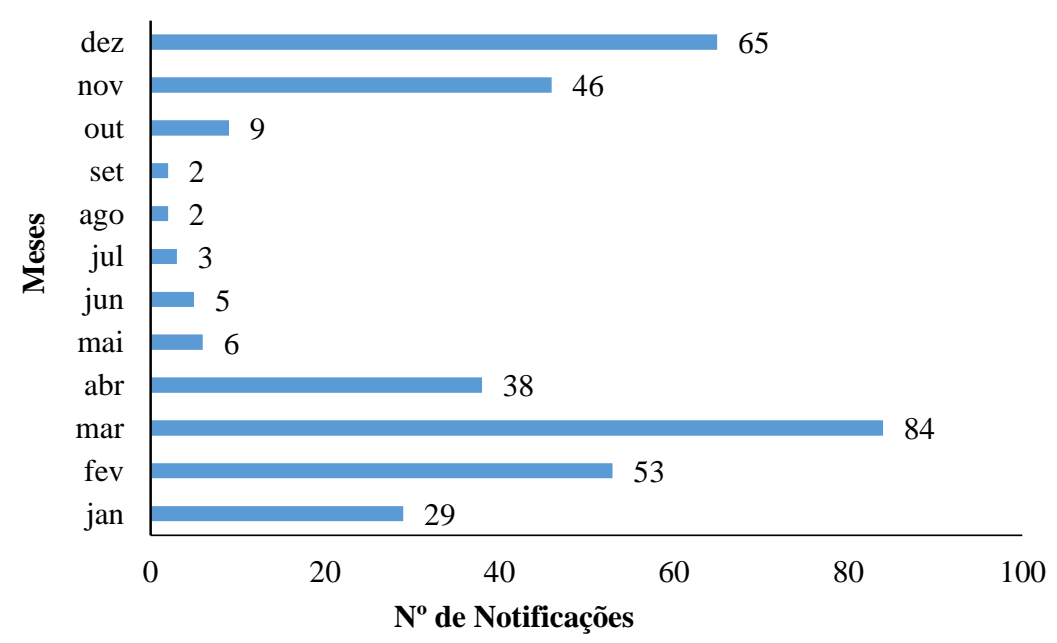

Fonte: Elaborado pelos autores, 2020. 
No município de Ilha Solteira pode-se observar notificações de casos de dengue durante todos os meses do ano. Nota-se um aumento significativo nas notificações dos meses de novembro a abril, onde concentraram-se 79,5\% delas. Este período compreende uma época de maior precipitação na região, assim como de médias de temperatura e umidade mais elevadas (Figura 2), sendo estes fatores fundamentais para aumento da infestação do vetor Aedes aegypti. A doença tem padrão sazonal, apresentando número maior de casos nos cinco primeiros meses do ano, período considerado mais quente e úmido, típico dos climas tropicais (TANNOUS, 2018).

Figura 2. Indice médio mensal pluviométrico, umidade relativa mensal média e temperatura mensal média relacionados a ocorrência média de notificações de dengue no Município de Ilha Solteira, São Paulo, no periodo de 2016, 2017 e 2018.

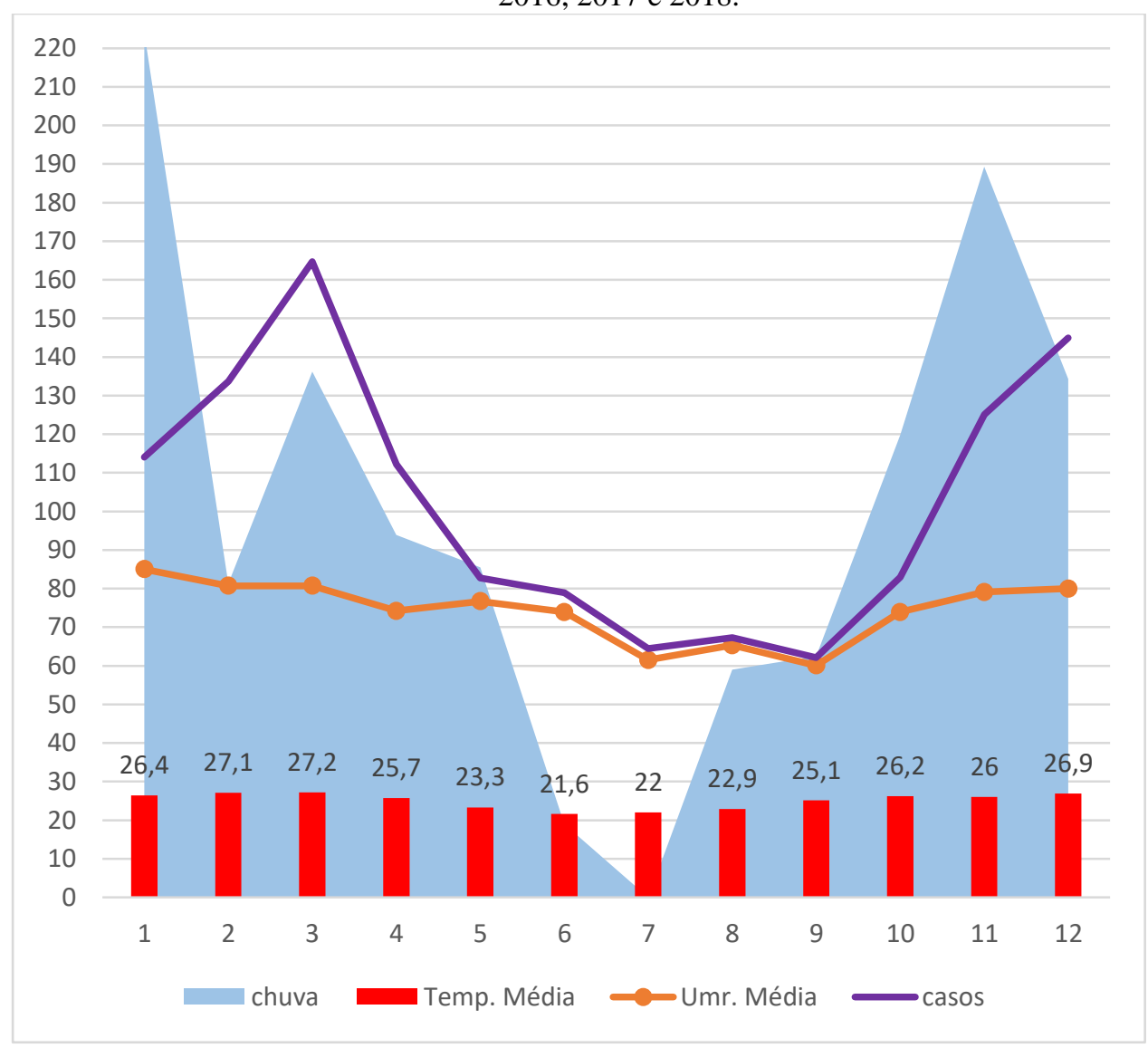

Fonte: Elaborado pelos autores, 2020.

Nota-se, na Figura 2, que a temperatura, umidade e a precipitação começaram a aumentar gradativamente em setembro, se acentuando em outubro e um mês depois, novembro, ocorreu o aumento acentuado do número de casos de dengue. Dados estes semelhantes aos encontrados por Tannous (2018), que evidenciou a relação entre o aumento das chuvas e um maior número de casos de dengue, em especial nos meses seguintes após o início do período chuvoso.

A região do município tem a temperatura média anual de $23.6^{\circ} \mathrm{C}$, índice Pluvíométrico de $1.300 \mathrm{~mm}$ anuais, sendo classificado como tropical chuvoso de bosque, apresentando chuvas no verão e estiagem no inverno (PGIRS, 2012). 
De acordo com Tannous (2018), em pesquisa realizada em Jataí/GO, os casos de dengue foram registrados durante todos os meses do ano, como os dados deste trabalho. Porém, os picos de ocorrência foram entre fevereiro e maio. Os dados pluviométricos da região de Jataí/GO registraram maior incidência de chuvas no primeiro semestre do ano, mais especificamente de janeiro a abril.

Estudo realizado em Araraquara no período de 1991 a 2015 detectou a ocorrência de 16.431 casos notificados, e a maior incidência ocorreu nos meses de março a maio, após o aumento da pluviosidade que iniciou-se em janeiro, aumentando assim a infestação do vetor (FERREIRA; CHIARAVALLOTI NETO; MONDINI, 2018). Desta forma fica evidente que os altos níveis de infestação do Aedes aegypti aumentam com as chuvas e refletem no aumento da taxa de incidência da doença, sendo necessário intensificar as ações de vigilância antes destes períodos.

\section{Caracterização dos indivíduos acometidos}

Figura 3. Distribuição de notificações de dengue segundo o gênero, em Ilha Solteira, no período de 2016 a 2018. Ilha Solteira, São Paulo, Brasil, 2020.

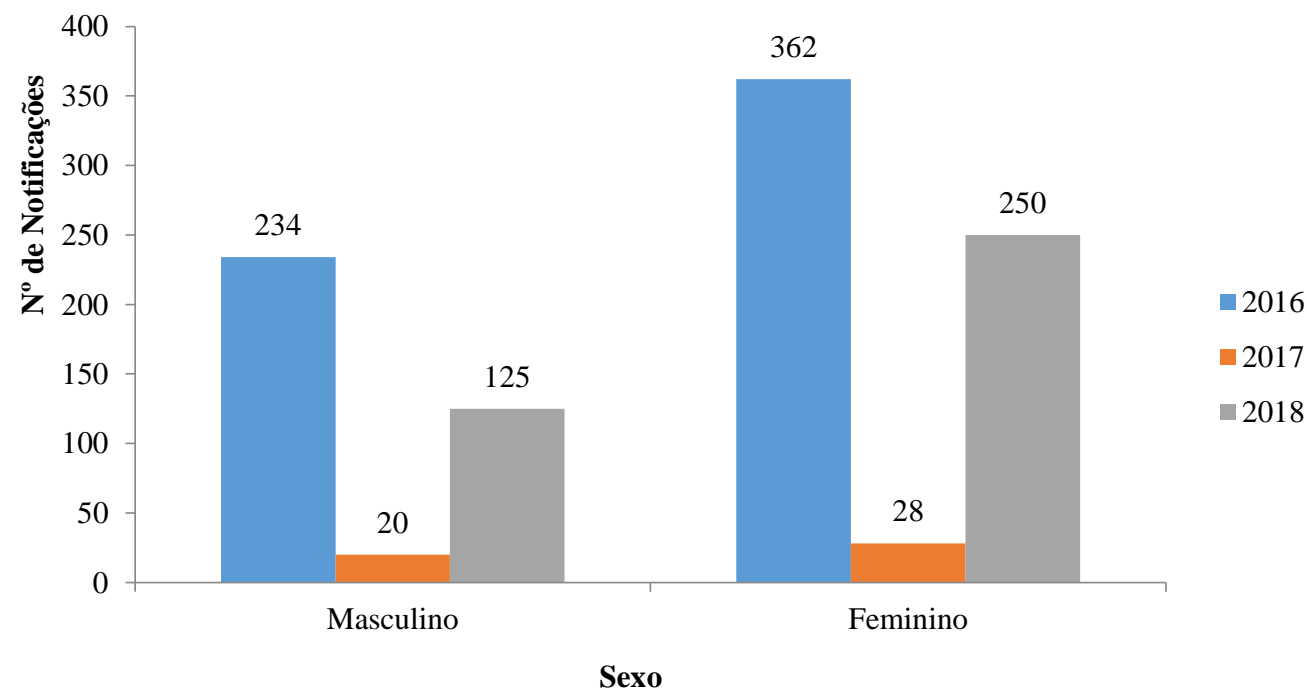

Fonte: Elaborado pelos autores, 2020.

A ocorrência das notificações de acordo com o sexo do indivíduo acometido durante o período de estudo foi de $62,8 \%$ do sexo feminino e $37,2 \%$ do sexo masculino. Outros estudos corroboraram com este, como o realizado em Londrina/PR, onde se demonstrou a maior frequência de casos em indivíduos do sexo feminino, representando 53,86\% (GIANGIACOMO, 2015).

A predominância de casos em mulheres é justificada pelo fato desta parcela da população permanecer por mais tempo no ambiente intradomicilio ou peridomicilio, locais onde ocorrem a 
maior transmissão da doença devido ao hábito do vetor (BASTOS, 2004; MONTEIRO et al., 2009).

Outra possível explicação é o fato das mulheres procurarem os serviços de saúde com maior frequência em caso de sintomas mesmo que brandos (BASTOS, 2004).

Com relação a distribuição das notificações por faixa etária, os indivíduos notificados foram divididos conforme a "Pirâmide de idade". Esta divisão é a representação gráfica da estrutura de uma população, onde divide-se 0 - 4 anos, 5 - 9 anos, 10 - 14 anos, 15 - 19 anos, 20 - 24 anos, 25 - 29 anos, 30 - 34 anos, 35 - 39 anos, 40 - 44 anos, 45 - 49 anos, 50 - 54 anos, 55 - 59 anos, 60 - 64 anos, 65 - 69 anos, 70 - 74 anos e 75 e mais anos (SILVA ; ANDRADE, 2014).

Figura 4. Distribuição de notificações de dengue segundo a faixa etária, em Ilha Solteira, no período de 2016 a 2018. Ilha Solteira, São Paulo, Brasil, 2020.

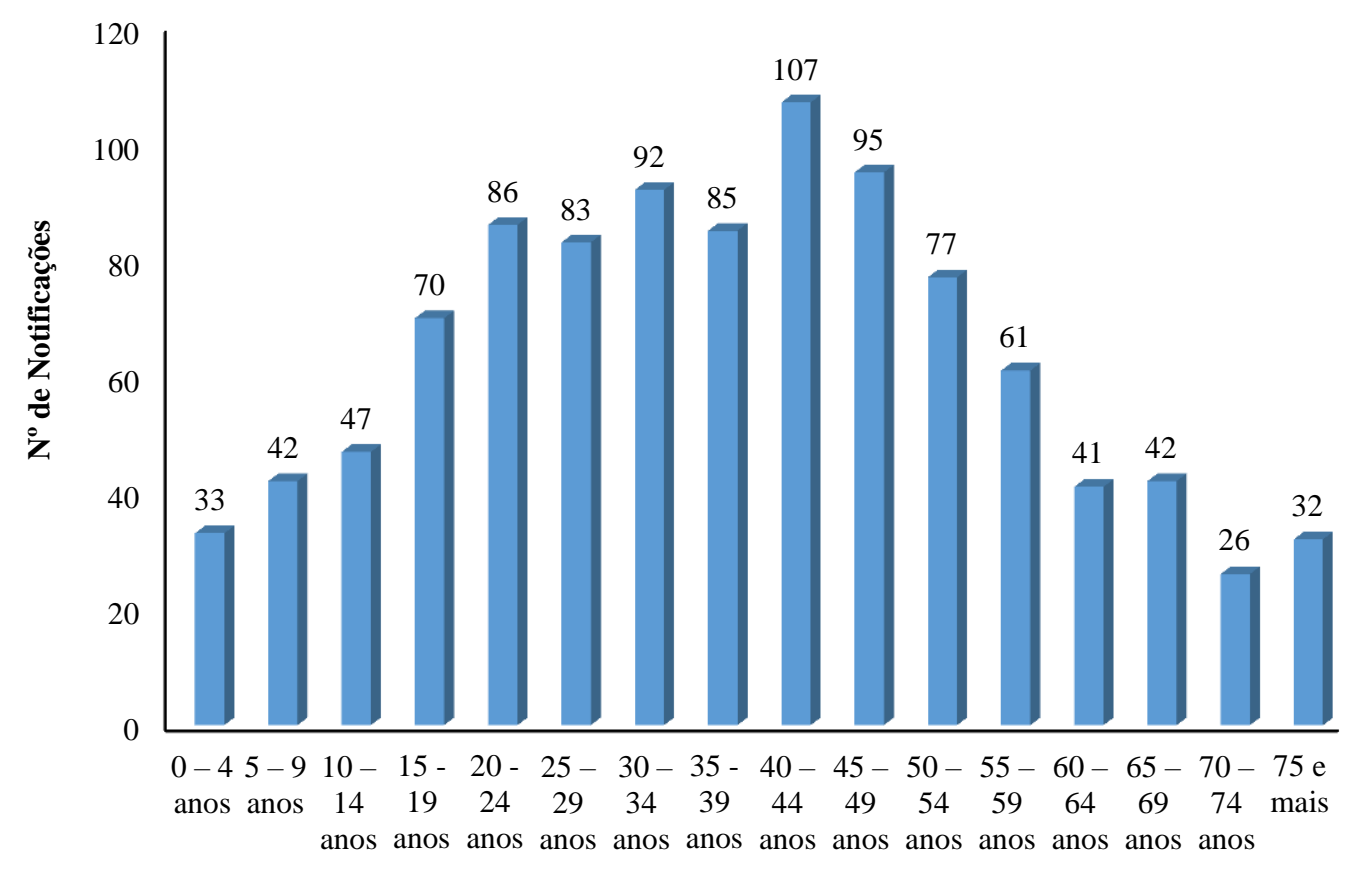

Faixa Etária

Fonte: Elaborado pelos autores, 2020.

Dentre as faixas etárias, destacou-se a 40 - 44 anos, com 107 notificações. Porém, vale destacar, que a idade entre 20 e 59 anos foram responsáveis por 67,3\% das notificações. Este dado demonstra que os indivíduos economicamente ativos foram mais acometidos pela doença. Estudo realizado em Araraquara/SP corroborou com os dados encontrados neste, pois a faixa etária com o maior número de notificações encontrava-se entre 20 e 59 anos, assim como o realizado em Fortaleza/CE cuja faixa etária mais afetada foi de 19 a 59 anos (FERREIRA et al., 2018; LIMA et al., 2019). 


\section{Caracterização do perfil demográfico}

A cidade de Ilha Solteira foi planejada durante a construção da hidrelétrica com o mesmo nome. A princípio foi dividida em duas regiões: zona norte e zona sul. Havia uma hierarquização das moradias e uma divisão social do espaço. A cada um desses níveis, correspondia um tipo de habitação, padronizadas seguindo as diretrizes arquitetônicas adotadas (CESP, 1982).

Dessa forma, na zona sul foi construído as moradias para os trabalhadores de nível hierárquico alto e médio (nível 6, 5, 4,3) e na zona norte ficavam as casas dos trabalhadores de nível médio e mais baixo (nível 4, 3, 2, 1) (DOURADO et al., 2003).

A partir da década de 80 iniciou-se a política de privatização. O fortalecimento de Ilha Solteira dependia do desenvolvimento econômico de toda a região. Medidas para a transformação do núcleo urbano em cidade permanente foram implementadas a partir de 1980, como o cadastramento e a colocação à venda, no mercado imobiliário, dos imóveis da cidade, como habitações e lojas comerciais e particulares dos comerciantes, bem como de terrenos e indústrias (VIANA, 2020).

Ilha Solteira iniciou então o processo de assumir sua própria identidade, com seu espaço urbano sendo transformado em função das diferentes atividades de seus moradores. No entanto, a dinâmica da divisão por níveis sociais inicial prevaleceu, e os bairros populares continuaram a ser construídos na zona norte, como o Bairro Bela Vista, Jardim Aeroporto, Novo Horizonte, CDHU, Morada do Sol, enquanto na zona sul foram construídos bairros de alto padrão como Morumbi e Santa Catarina (VIANA, 2020).

Nas notificações avaliadas, alguns bairros foram discriminados. No entanto, a maioria foram identificados como Zona rural, que compreendem o Cinturão Verde, Rocinha Familiar e os Assentamentos; Zona Sul; Zona Norte; e Centro.

Algumas áreas têm localização específica e por isso foram elencados como bairros distintos, como o Recanto das Águas (Chácaras localizadas as margens do Rio Paraná), Ipê (bairro inicialmente rural, mas que atualmente está no perímetro urbano), e Porto (composto pela população ribeirinha). 
Figura 5. Distribuição das notificações de Dengue por bairros no município de Ilha Solteira, SP de 2016 a 2018 . Ilha Solteira, São Paulo, Brasil, 2020.

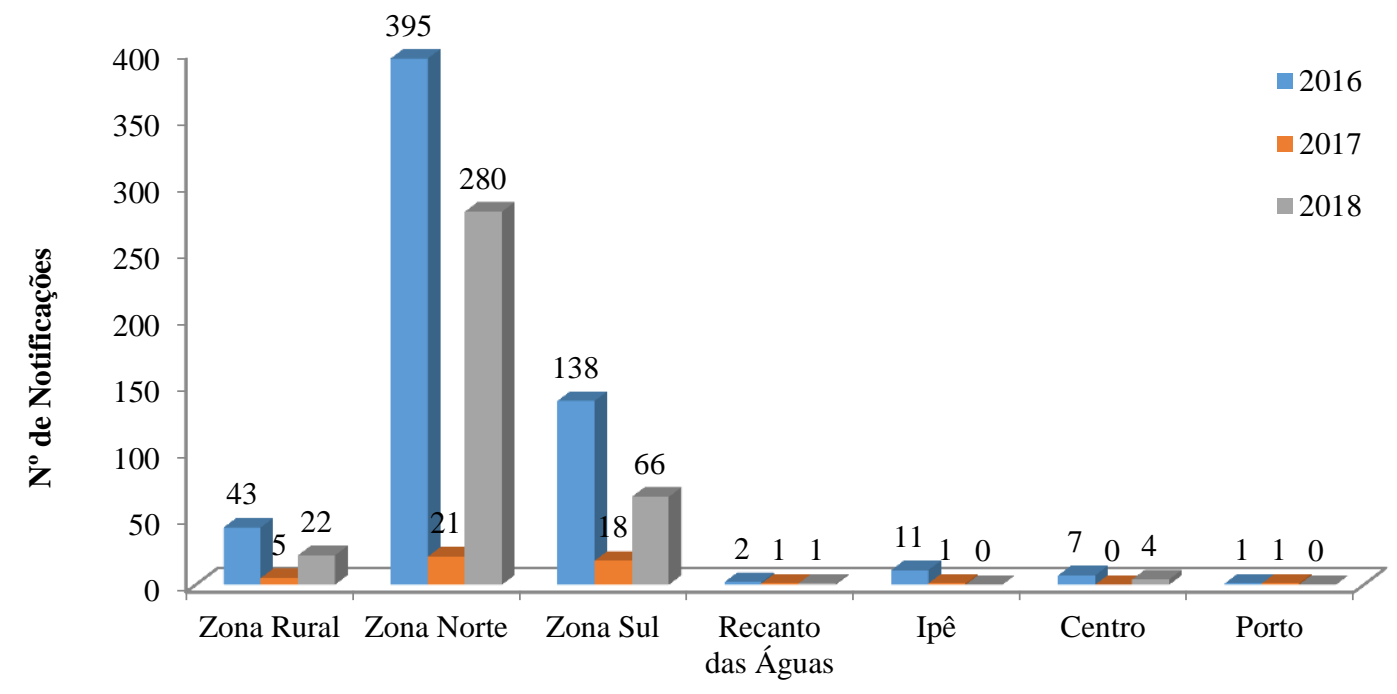

Bairros

Fonte: Elaborado pelos autores, 2020.

Os dados demonstram que a maioria das notificações se concentraram na zona norte do município, o correspondente no ano de 2016 a 66\% das notificações, em 2017 a $44 \%$ e 2018 a $74 \%$. Esta região é a mais populosa da cidade que cresceu de forma não planejada e o local onde encontra-se a maioria da população carente, que vive em condições precárias. Desta forma, encontra-se neste bairro condições ambientais favoráveis de criadouros e disseminação do vetor. A rápida urbanização, condições precárias de vida da população, aliadas as falhas de vigilância e controle do vetor são fatores fundamentais para a dispersão do vírus da dengue (FERREIRA, 2012; B ̈̈CK; LUNDKVIST, 2013).

Com relação a ocorrência de notificações em bairros da Zona Sul, a maioria destes sãos provenientes do Bairro Santa Catarina, que possui um loteamento com muitos terrenos baldios e construções, características que colaboram com a manutenção de criadouros do vetor.

Outra região que também merece atenção é a zona rural que em 2016 foi responsável por 7\% das notificações, em 2017 por 10,4\%, e em 2018 por 6\%. Nesta região, os fatores que podem propiciar a disseminação dos casos são o aumento da aglomeração da população em determinados locais (assentamentos) e o descarte de resíduos nas estradas vicinais, pela população e por praticantes de caminhada e corrida na rodovia perimetral.

Ao traçar o perfil demográfico do dengue para cada um dos anos analisados observou-se que a maioria dos casos notificados são de habitantes residentes na zona urbana do município (98,6\%). Em estudo desenvolvido no município de Itu, SP, observaram-se a auto correlação espacial entre áreas centrais e periféricas, enquanto o risco relativo da doença possui maior 
predomínio na parte central, mas não permite afirmar a ausência do risco de ocorrências nas demais áreas (FERREIRA et al., 2017).

Em estudo realizado em Jataí, GO, a maioria dos casos também ocorreu na zona urbana do município, o correspondente no ano de 2014 a 93,75\%, em 2015 a 96,85\% e em 2016 a 75,62\% (GABRIEL et al., 2018). Ujvari (2003) demonstrou que 80\% dos indivíduos infectados residem em centros urbanos e que estes centros propiciam condições ambientais favoráveis de criadouros e disseminação do vetor devido a elevada produção de resíduos sólidos.

Também de acordo com Mendonça (2009), a geração de dejetos, reservatórios, e resíduos lançados nas ruas, em loteamentos e em áreas públicas dos grandes centros urbanos são criadouros que acumulam água das chuvas e contribuem para o desenvolvimento e disseminação do Aedes aegypti.

Segundo Hino et al.(2010) e Lupi et al.(2007) a dengue é uma doença essencialmente urbana, pois nesse ambiente existem todos os fatores determinantes para sua ocorrência. Porém, Rocha 40 afirmou que a ocorrência da dengue pode variar entre as localidades, onde o aspecto urbano-social pode criar ambientes favoráveis à proliferação do Aedes aegypti.

\section{Caracterização da doença nos indivíduos notificados}

Geralmente, a dengue clássica apresenta como principais sintomas febre alta de início abrupto (em torno de $39^{\circ}$ a $40^{\circ}$ ), cefaleia intensa (principalmente na região frontal), mialgia, prostração, artralgia, dor retro-orbitária, náusea, vômito, anorexia, astenia e exantema. Além disso, podem ocorrer manifestações hemorrágicas, como petéquias, epistaxe, gengivorragia, sangramento gastrointestinal, hematúria e metrorragia (DENIS et al., 2003; LUPI et al., 2010).

Quando avaliados os sintomas presentes nos indivíduos, notou-se que os sintomas clássicos da dengue estavam presentes em todos os casos notificados (Figura 6). 
Figura 6. Sintomas apontados nas notificações de dengue, em Ilha Solteira, no período de 2016 a 2018. Ilha Solteira, São Paulo, Brasil, 2020.

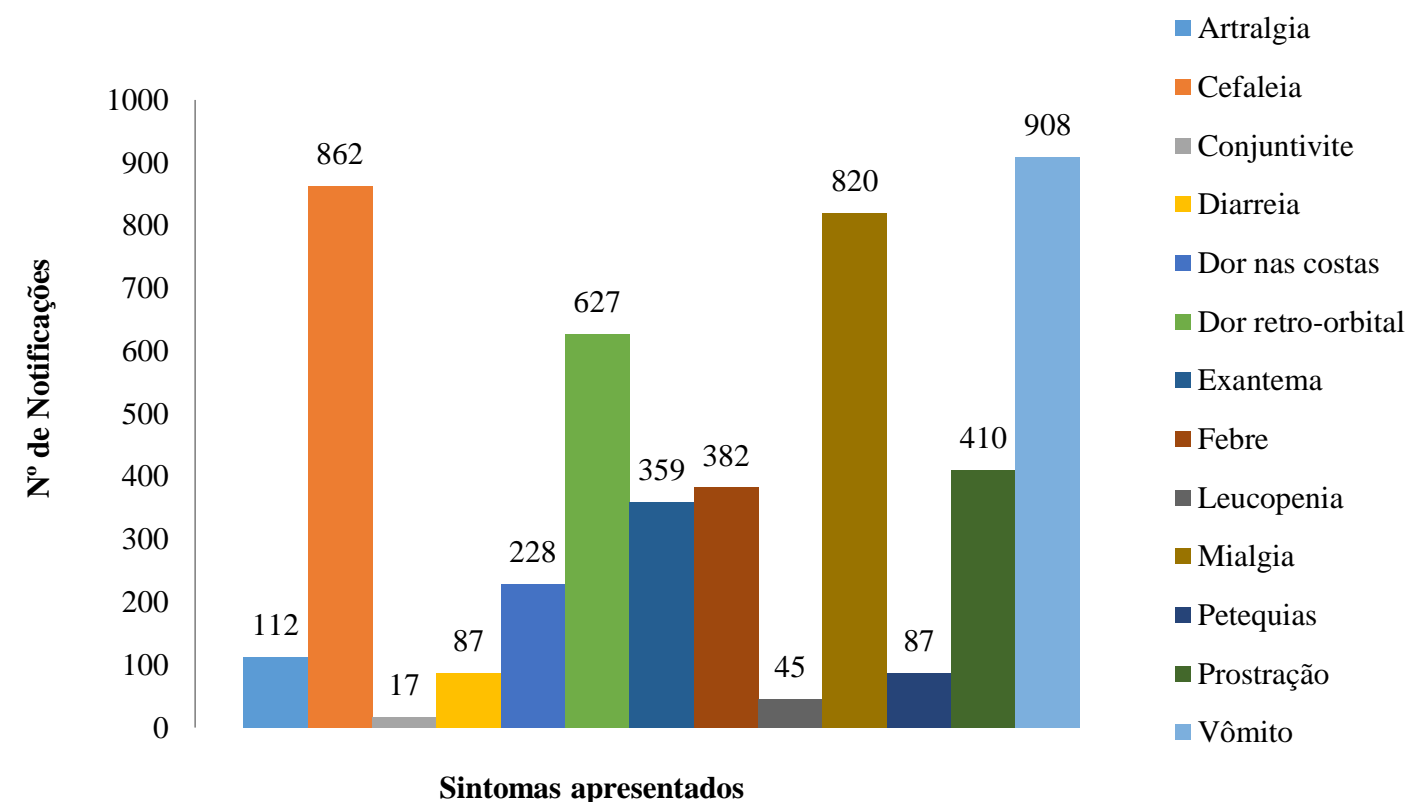

Fonte: Elaborado pelos autores, 2020.

Com relação aos sintomas que estavam mais presentes nos pacientes atendidos com suspeita de dengue no periodo de estudo, $89,1 \%$ apresentaram vômito, 84,6\% cefaleia, 80,5\% mialgia, e $61,5 \%$ dor retro-orbital.

$\mathrm{Na}$ fase febril da dengue ocorre a manifestação de febre imediata com duração de dois a sete dias, associada a sinais de cefaleia, mialgia, artralgia, dor retro-orbitária, náuseas e vômitos. Geralmente, após esta fase ocorre a recuperação dos pacientes, mas se isso não ocorrer, a doença pode evoluir para quadro grave de dengue hemorrágica (Brasil, 2017).

No período estudado, não ocorreu caso de dengue hemorrágica em Ilha Solteira.

\section{Confirmação dos casos notificados}

Para que seja realizada a notificação de um caso suspeito de dengue, o paciente deve ser avaliado clinicamente, porém a confirmação sorológica deve ser realizada por meio de exame de detecção de anticorpos virais. Esta confirmação sorológica, deve ser solicitada de acordo com recomendações da Vigilância Epidemiológica, que geralmente orienta que em casos não edêmicos o exame seja solicitado a todos os pacientes suspeitos e, em períodos epidêmicos deverá ser solicitado a todo paciente grave suspeito e em $10 \%$ dos casos suspeitos de dengue clássica (BRASIL, 2009; DIAS et al., 2010). 
Tabela 1. Casos confirmados de dengue pela realização de sorologia no município de Ilha Solteira de 2016 a 2018. Ilha Solteira, São Paulo, Brasil, 2020.

\begin{tabular}{|c|c|c|c|}
\hline \multirow{2}{*}{ Status } & \multicolumn{3}{|c|}{ Anos } \\
\hline & 2016 & 2017 & 2018 \\
\hline Notificações & 596 & 48 & 375 \\
\hline Confirmados sorologicamente & 243 & 2 & 110 \\
\hline Não realizado sorologia & 347 & 23 & 202 \\
\hline Negativo pela sorologia & 6 & 23 & 63 \\
\hline
\end{tabular}

Fonte: Elaborado pelos autores, 2020.

No periodo avaliado foi realizada sorologia em 43,9\% dos casos suspeitos notificados, um número elevado quando comparado ao sugerido pelas Diretrizes Nacionais para a Prevenção e Controle de Epidemias de Dengue que é de 10\% dos casos suspeitos de dengue clássica (SILVA ; SANTOS, 2018).

Não ocorreu casos graves da doença no municipio pesquisado neste período e todos os pacientes evoluíram para a cura. Pode-se notar também que a taxa de positividade média para dengue confirmada pela sorologia, dentre as notificações realizadas no período de estudo foi de $79,4 \%$.

Dados semelhantes foram observados por Silva; Santos (2018), no município de governador Valadares/MG, em 2017, que registraram 263 notificações da doença, e destas, 184 $(69,96 \%)$ apresentaram dengue clássica e 79 (30,04\%) foram consideradas negativas. Não houve caso inconclusivo, nem dengue com complicações.

Considerando que no período de estudo foram notificadas 1019 casos suspeitos e, destes, $79,4 \%$ eram positivos, podemos sugerir que o municipio apresentou 810 casos confirmados de dengue. A incidência anual foi de, 915,6 casos por 100 mil habitantes em 2016; 7,5 casos por 100 mil habitantes em 2017; e 414,4 casos por 100 mil habitantes em 2018. O Ministério da Saúde classifica como baixa incidência quando o número de casos autóctones for menor do que 100 casos por 100.000 habitantes, desta forma, o município apresentou alta incidência em 2016 e 2018. No estado do Paraná, em 2018, a incidência foi de 0,51 casos por 100.000 hab. (SESA, 2020).

Para ter sucesso no controle e prevenção e tornar o município com risco baixo para a doença, a vigilância deve ser realizada a fim de detectar epidemias de forma precoce. O início do período chuvoso é um indicativo para iniciar as medidas de controle da doença. Por isso, recomenda-se que neste período a vigilância inicie a busca ativa dos casos e do vetor, e a partir daí intensifique as medidas de controle do vetor e ações educativas para a população (KULARATNE, 2015). 
Mesmo em municípios de pequeno porte como o deste estudo, a prevenção e o combate à dengue devem levar em conta o perfil epidemiológico de cada região da cidade, pois entende-se que cada bairro tem reguladores próprios no processo endêmico da dengue. Como em Ilha Solteira existe pouca migração, seria interessante estabelecer os padrões da dengue em cada área, o que possibilita construir um banco de dados para antecipar as ações de prevenção à doença nos períodos mais críticos.

Dessa forma, o município pode direcionar ações específicas de controle do vetor em cada área, inclusive de educação ambiental para a população, seguindo o mapa epidemiológico do local.

\section{CONCLUSÃO}

Com a realização desta pesquisa pode-se concluir que o município é suscetível a ter epidemias de dengue entre os meses de novembro a abril, sendo sua incidência aumentada na zona urbana, em bairros populosos da cidade, tornando-se um problema de saúde pública, o que exige da administração ações de vigilância sanitária mais eficientes, como a capacitação da equipe de saúde para notificar e encaminhar os casos para os procedimentos médicos necessários.

Ações educativas também poderão ser eficazes no controle da dengue. Neste contexto, as campanhas de esclarecimento e prevenção da dengue direcionado à população poderão criar uma cultura de combate intensivo ao vetor. Com isso, espera-se agregar novos conhecimentos a população e aos profissionais de saúde para melhorar o entendimento sobre a dengue e fornecer subsídios para a implementação de políticas públicas envolvendo várias secretarias de governo: saúde, educação, meio ambiente/saneamento básico e habitação; além disso, o desenvolvimento de ações intersetoriais visando a melhoria da qualidade de vida e de saúde da população.

\section{REFERENCIAS}

BÄCK, A.T.; LUNDKVIST, A. Dengue viruses - an overview. Infection Ecology \& Epidemiology, v.3, n.1, p.1-9, 2013. DOI: http://dx.doi.org/10.3402/iee.v3i0.19839

BASTOS, M. S. Perfil soroepidemiológico do dengue diagnosticado na Fundação de

Medicina Tropical do Amazonas (1998-2001). Dissertação (Mestrado em Ciências na área de Saúde Pública). Universidade Federal do Amazonas. Manaus, AM, 2004.

BRASIL. Ministério da Saúde. Descrição da doença. 2015. Disponível em: https://www.saude.gov.br/saude-de-a-z/dengue/descricao-da-doenca. Acesso em: 14 jan. 2020.

BRASIL. Ministério da Saúde. Guia de Vigilância em Saúde. 2 ed. Brasília: Ministério da Saúde, 2017. 
BRASIL. Ministério da Saúde. Secretaria de Vigilância em Saúde. Departamento de Vigilância epidemiológica. Diretrizes Nacionais para a Prevenção e Controle de Epidemias de Dengue. Série A. Normas e Manuais Técnicos. Brasília: Ministério da Saúde, 2009.

BRASIL. Ministério da Saúde. Secretaria de Vigilância em Saúde. Guia de Bolso. Doenças infecciosas e parasitárias. 8 ed. Série B. Textos Básicos de Saúde. 8 ed. Brasília: Ministério da Saúde, 2010.

BRASIL. Ministério da Saúde. Secretaria de Vigilância em Saúde. Situação epidemiológica e estratégias de prevenção, controle e eliminação das doenças tropicais negligenciadas no Brasil, 1995 a 2016. Brasília: Ministério da Saúde, v.49, 2018.

BRASIL. Portaria $n^{0} \mathbf{2 . 4 7 2}$ de agosto de 2010. Define as terminologias adotadas em legislação nacional, conforme disposto no Regulamento Sanitário Internacional 2005 (RSI 2005), a relação de doenças, agravos e eventos em saúde pública de notificação compulsória em todo o território nacional e estabelecer fluxo, critérios, responsabilidades e atribuições aos profissionais e serviços de saúde. 2010. Disponível em:

http://bvsms.saude.gov.br/bvs/saudelegis/gm/2010/prt2472_31_08_2010.html. Acesso em: 14 jan. 2020.

CESP. Companhia Energética de São Paulo. Divisão de Arquitetura e Urbanismo. Vilas temporárias e permanentes do setor elétrico: a experiência da CESP. São Paulo: CESP, 1982.

COSTA, F. S.; SILVA, J. J.; SOUZA, C. M.; MENDES, J. Dinâmica populacional de Aedes aegypti (L) em área urbana de alta incidência de dengue. Revista da Sociedade Brasileira de Medicina Tropical, v.41, n.3, p.309-312, 2008. https://doi.org/10.1590/S003786822008000300018.

DENIS, C. K.; CAVALCANTI, K. M.; MEIRELlES, K. C.; MARTINELLI, B. Manifestações otorrinolaringológicas em pacientes com dengue. Revista Brasileira de Otorrinolaringologia, v.69, n.5, p.644-647, 2003. https://doi.org/10.1590/S0034-72992003000500009

DIAS, L. B. A.; ALMEIDA, S. C. L.; HAES, T. M.; MOTA L.M.; RORIZ-FILHO, J.S. Dengue: transmissão, aspectos clínicos, diagnóstico e tratamento. Medicina, v.43, n.2, p.143-52, 2010.

DOURADO, L. A. C.; SILVA, E. A.; HERNANDEZ, F. B. T.; VANZELA, L. S. Ilha Solteira contraste de uma cidade planejada. In: ENCONTRO SUL-MATOGROSSENSE DE

GEOGRAFIA, XVII. Anais... 2003. Ilha Solteira: Universidade Estadual Paulista. Três Lagoas, MS.

FERREIRA, A.C.; CHIARAVALLOTI NETO, F.; MONDINI, A. Dengue em Araraquara, SP: epidemiologia, clima e infestação por Aedes aegypti. Revista de Saúde Pública, v.52, n.18, p.110, 2018. https://doi.org/10.11606/S1518-8787.2018052000414.

FERREIRA, G. L. C. Global dengue epidemiology trends. Revista do Instituto de Medicina Tropical de São Paulo, v.54, n.18, p.S5-6, 2012. https://doi.org/10.1590/s003646652012000700003 
FERREIRA, H. H.; LOPES, E. R. N; SOUZA C.; SOUZA, J. A. P.; LOURENÇO, R. W. Avaliação Espacial da Dengue na Área Urbana de Itu - São Paulo. Revista do Departamento de Geografia Universidade de São Paulo, v.33, 106-116, 2017.

https://doi.org/10.11606/rdg.v33i0.128515.

GABRIEL, A. F. B.; ABEL, K. C.; GUIMARÃES, M. P.; MIRAGLIA, S. G. K. Avaliação de impacto à saúde da incidência de dengue associada à pluviosidade no município de Ribeirão Preto, São Paulo. Cadernos de Saúde Coletiva, v.26, n.4, p.446-452, 2018.

GIANGIACOMO, G. M. Perfil epidemiológico da dengue no município de Londrina, PR no período de 2009 a 2014. Trabalho de Conclusão de Curso (Graduação em Odontologia). Universidade Estadual de Londrina. Londrina, PR, 2015.

HINO, P.; SANTOS, C. C.; SANTOS, M. O. CUNHA, T. N.; SANTOS, C. B. Evolução temporal da dengue no município de Ribeirão Preto, São Paulo, 1994 a 2003. Ciência ; Saúde Coletiva, v.5, n.1, p.233-238, 2010. https://doi.org/10.1590/S1413-81232010000100028

IBGE. Instituto Brasileiro de Geografia e Estatística. Panorama. Disponível em: https://cidades.ibge.gov.br/brasil/sp/ilha-solteira/. Acesso em: 15 abr. 2019.

KULARATNE, S. A. M. Dengue fever. The BMJ, v. 351, p.27-31, 2015. https://doi.org/10.1136/bmj.h4661.

LEAL, A. Dengue, zika e chikungunya mataram quase 800 pessoas em 2016 no Brasil. 2017. Disponível em: http://agenciabrasil.ebc.com.br/>. Acesso em: set. 2019.

LIMA, G. A.; LIMA, F. E. T.; NASCIMENTO, I. C. F.; RODRIGUES, R. R.; ROCHA, D. M. A.; COSTA, C. O.; CUSTODIO, I. L.; SANDOVAL, L. J. S. Casos de dengue em Fortaleza: um estudo epidemiológico documental. Brazilian Applied Science Review, v.3, n.5, p.2252-2262, 2019. https://doi.org/10.34117/basrv3n5-027

LUPI, O.; CARNEIRO, C. G.; COELHO, I. C. B. Manifestações mucocutâneas da dengue. Anais Brasileiros de Dermatologia, v.82, n.4, p.291-305, 2007.

MENDONÇA, F. A.; SOUZA, A. V. E.; DUTRA, D. A. Saúde pública, urbanização e dengue no Brasil. Sociedade ; Natureza, v.21, n.3, p. 257-269, 2009. https://doi.org/10.1590/S198245132009000300003.

MONTEIRO, E. S. C.; COELHO, I. S.; CUNHA, I.S.; CAVALCANTE, M. A.; CARVALHO, F. A. A. Aspectos epidemiológicos e vetoriais da dengue na cidade de Teresina, Piauí - Brasil, 2002 a 2006. Epidemiologia e Serviços de Saúde, v.18, n.4, p.365-374, 2009.

http://dx.doi.org/10.5123/S1679-49742009000400006.

OMS. Organização Mundial da Saúde (OMS). Diretrizes de dengue para diagnóstico, tratamento, prevenção e controle: nova edição. Geneva: World Health Organization, 2009.

PEREIRA, M. G. Epidemiologia e Prática. Rio de Janeiro: Guanabara Koogan, 2014.

PREMISA. Prefeitura Municipal de Ilha Solteira. Plano de Gestão Integrada de Resíduos

Sólidos. 2012. Disponível em: http://arquivo.ambiente.sp.gov.br/cpla/2017/05/ilha-solteira.pdf. Acesso em: 15 abr. 2019. 
ROCHA, R. C. Epidemiologia da dengue na cidade de Rio Branco- Acre, Brasil, no período de 2000 a 2007. Tese (Doutorado em Saúde Pública). Universidade de São Paulo. São Paulo, SP, 2011.

SECRETARIA DE ESTADO DA SAÚDE. Coordenadoria de Controle de Doenças. Superintendência de Controle de Endemias. Instituto Adolfo Lutz. Identificação do sorotipo DENV 4, GVE 29: São José do Rio Preto, municípios de São José do Rio Preto e Paulo de Faria, SP, Brasil. Boletim Epidemiológico Paulista, v.8, n.89, p.25-28, 2011.

SECRETARIA DE ESTADO DA SAÚDE. DRS II - Araçatuba. 2019. Disponível em: http://www.saude.sp.gov.br/ses/institucional/departamentos-regionais-de-saude/drs-ii-aracatuba. Acesso em: 10 dez. 2019.

SESA. Secretaria da Saúde do Paraná. Dengue: Características clínicas e epidemiológicas. Disponível em: http://www.dengue.pr.gov.br/modules/conteudo/conteudo.php?conteudo=11. Acesso em: 18 jan. 2020.

SESAU. Secretaria de Estado de Alagoas. Superintendência de Vigilância em Saúde. Saúde Alagoas: Análise da Situação de Saúde 2017. Alagoas, 2017. Disponível:

http://www.saude.al.gov.br/wp-content/uploads/2018/06/ASS-2017-ALAGOAS-FINAL.pdf. Acesso em: 14 jun. 2019.

SILVA, G. M.; ANDRADE, A. M. S. S. Avaliação do perfil epidemiológico da dengue no município de Paripiranga, Bahia, Brasil. Scientia Plena, v.10, n.9, p.1-11, 2014.

SILVA, P. L. N.; OLIVEIRA, R. S.; LOPES, T. R. C.; OLIVEIRA, E. M. S.; SOUTO, S. G. T.; PRADO, P. F. Notificações de doenças compulsórias e dos agravos em um hospital universitário de Minas Gerais, Brasil. Revista de Enfermagem UFSM, v.4, n.2, p.237-246, 2014. https://doi.org/10.5902/2179769210676.

SILVA, V. G.; SANTOS, W. B. Incidência de dengue nos anos de 2016 e 2017 no Bairro Santa Rita em Governador Valadares/MG. Enciclopédia Biosfera, v.15, n.28, p.1-10, 2018. https://doi.org/0.18677/EnciBio_2018B98.

TANNOUS, I. P. Perfil epidemiológico e geográfico da infecção pelo vírus da dengue em um município do sudoeste de Goiás: um estudo transversal. Dissertação (Mestrado em Ciências Aplicadas à Saúde). Universidade Federal de Goiás. Jataí, GO, 2018.

TAUIL, P. L. Aspectos críticos do controle do dengue no Brasil. Cadernos de Saúde Pública, v.18, n.3, p.867-871, 2002. https://doi.org/10.1590/S0102-311X2002000300030.

UJVARI, S. C. A história e suas epidemia: a convivência do homem com os microrganismos. 2 ed. Rio de Janeiro: Editora Senac, 2003.

VIANA, D. V.; IGNOTTI, E. A ocorrência da dengue e variações meteorológicas no Brasil: revisão sistemática. Revista Brasileira de Epidemiologia, v.16, n.2, p.240-256, 2013. https://doi.org/10.1590/S1415-790X2013000200002

VIANNA, M. P. Ilha Solteira: de patrimônio industrial a polo de desenvolvimento regional. Disponível em: 
http://portal.iphan.gov.br/uploads/ckfinder/arquivos/VI_coloquio_t2_ilha_solteira.pdf. Acesso em: 10 fev. 2020.

WHO. World Health Organization. Dengue and severe dengue. Fact sheet. Updated July 2016.

Disponível em: http://www.who.int/mediacentre/factsheets/fs117/en/. Acesso em: 10 fev. 2020. 